\title{
USO PÚBLICO NAS RESERVAS PARTICULARES DO PATRIMÔNIO NATURAL - CONVERGÊNCIA ENTRE TURISMO E CONSERVAÇÃO AMBIENTAL NO BRASIL
}

\author{
Murilo de Alencar Souza Oliveira \\ Doutorando em Administração e Turismo da Universidade do Vale do Itajaí - UNIVALI \\ Professor da Faculdade do Litoral Catarinense - FLC/SOCIESC \\ malencar@fiocruz.br
}

Paulo dos Santos Pires

Doutor em Geografia pela Universidade de São Paulo - USP

Professor da Universidade do Vale do Itajaí - UNIVALI

pires@univali.br

\section{RESUMO}

O trabalho abordou o uso público nas Reservas Particulares do Patrimônio Natural/RPPNs como possibilidade de convergência entre atividades de turismo e conservação ambiental no país. Justifica-se as RPPNs como objeto de estudo por serem Unidades de Conversação/UCs ambiental, privadas, autorizadas à exploração econômica de seus recursos mediante uso público. $\mathrm{O}$ estudo consistiu de análise exploratória quantitativa por meio de pesquisa bibliográfica sobre Turismo, UCs e RPPNs, e pesquisa documental, baseada em dados secundários da Confederação Nacional de RPPNs [CNRPPN] de 2010. Para tratamento dos dados utilizou-se Análise de Conteúdo e para configuração de tabelas e gráficos dos resultados empregou-se planilha eletrônica MS-Excel. Apresentou-se o estado atual e distribuição geográfica de 931 RPPNs. Identificou-se 37 RPPNs que possuem atividades de uso público, compatibilizam atividades de turismo e conservação ambiental. Assim, podem obter recursos (taxas de acesso, hospedagem, passeios) para remunerar e capacitar funcionários, construir estruturas de apoio à pesquisa e regularizar e implementar seu funcionamento em prol da manutenção da biodiversidade. Conclui-se que as RPPNs podem realizar atividades de turismo aliadas a educação ambiental e melhoria de renda e condições de trabalho para as comunidades locais.

Palavras-chave: Ecoturismo; RPPNs; Uso Público; Sustentabilidade do Turismo.

\section{PUBLIC USE OF PRIVATE EQUITY RESERVES IN NATURAL - CONVERGENCE BETWEEN TOURISM AND ENVIRONMENTAL CONSERVATION IN BRAZIL}

\begin{abstract}
This work addresses the public use in the Private Natural Heritage Reserves (RPPNs) as the possibility of convergence between tourism activities and environmental conservation in the country. RPPNs can be justified as an object of study as these units Conversation / PAs environmental, private, authorized to economic exploitation of its resources through public use., since it is focused on sustainability itself and the surrounding communities. The study consisted of exploratory analysis through quantitative research literature on tourism, conservation areas and private reserves, and documentary research, based on secondary data from the National Confederation of RPPNs [CNRPPN] 2010. The data collected was used in content analysis and MSExcel spreadsheet was used to display the results in tables and graphsand presented the current status and geographical distribution of 931 private reserves. We identified 37 private reserves that have activities for public use, compatible tourism activities and environmental conservation, from respect for the ideals of sustainable development. Thus, they can obtain resources (access fees, lodging, tours) to compensate and empower employees, build structures to support research and to regulate and implement its operation for the maintenance of biodiversity. It is concluded that the RPPNs can do tourism activities coupled with environmental education and improvement of income and working conditions for local communities.
\end{abstract}

Keywords: Ecotourism; RPPNs; Public Use; Tourism Sustainability. 


\section{INTRODUÇÃO}

As relações do Homem com o meio ambiente requerem profunda reflexão quanto à imbricação entre as condições de vida da espécie humana e do planeta (fauna, flora e biosfera) neste início de milênio. A busca do crescimento econômico e acúmulo de riquezas com base no consumismo e uso inconsequente dos recursos naturais, tem resultado em constantes agressões ambientais com alterações climáticas, de ciclos bioquímicos e no ritmo de extinções de espécies, de resultado futuro imprevisível (Câmara, 2004). A natureza tem reagido a estas agressões conforme percebido nos fenômenos naturais mais extremados e rigorosos, que agravam os problemas econômicos, de saúde, habitação, água, saneamento, desertificação etc.

No segmento do Turismo estes efeitos se revelam muito mais visíveis (Dias, 2003), pois vários destinos turísticos localizados em regiões vulneráveis passam a não mais atrair pessoas e perdem as condições e benefícios de seu uso. Entretanto, o crescimento e consolidação do turismo, como atividade econômica e social, tem forte responsabilidade neste processo gerador de impactos ambientais. A lógica de lucros maiores no menor prazo possível, herdada da racionalidade capitalista, levou a despreocupação com o planejamento e gestão da atividade turística e com os possíveis impactos na natureza e nas comunidades residentes ao longo do tempo (Dias, 2008). Não houve a mensuração de sua viabilidade, das consequiências futuras e a preocupação com a formação de uma sociedade mais consciente quanto à conservação da natureza e seus recursos, essenciais ao próprio turismo.

Desta forma, se a conservação da natureza é imprescindível ao turismo, como afirma Petrocchi (1998), surgem alguns questionamentos: por que a atividade turística parece caminhar em direção oposta, rumo à destruição da natureza? O turismo pode ser uma atividade econômica praticada em áreas de conservação da natureza como forma de auxílio à manutenção destas áreas? Será que as reservas naturais particulares podem gerar recursos necessários a sua sustentabilidade, mediante atividades de uso público (visitação turística, recreação, educação ambiental e/ou pesquisa), porém sem perder o foco na sua finalidade precípua da conservação? A partir destas dúvidas, este trabalho utilizou a metodologia de análise exploratória do tipo quantitativa, limitada ao estudo das Reservas Particulares do Patrimônio Natural/RPPNs, com emprego de pesquisa bibliográfica e documental, sobre o estado atual e atividades de uso público desenvolvidas nestas reservas, com base em dados secundários da Confederação Nacional de RPPNs (CNRPPN, 2010). Para fins de tratamento dos dados utilizou-se a Análise de Conteúdo e para configuração de tabelas e gráficos de apresentação dos resultados empregou-se a planilha eletrônica MS-Excel.

Justifica-se a escolha das RPPNs como objeto de estudo por serem unidades de conversação ambiental de cunho privado, autorizadas a realização de atividades econômicas, desde que restritas ao uso público. Entende-se que estas práticas possam gerar melhorias nas condições de sustentabilidade (ambiental, social, econômica e de vida das comunidades ao redor). Para tal, tornou-se necessário efetuar levantamento histórico-conceitual sobre turismo, o Sistema Nacional de Unidades de Conservação/SNUC e RPPNs, apresentar o estado atual das RPPNs e sua distribuição geográfica e por bioma, além de identificar RPPNs que realizam atividades de uso público.

Para melhor consecução dos objetivos propostos, este trabalho foi estruturado em quatro capítulos, além da presente Introdução, que foram denominados de: 1. Marco Teórico; 2. O SNUC e a Conservação da Natureza nas RPPNS; 3. Estado Atual, Distribuição e Uso Público nas RPPNS; e 4. Considerações Finais.

\section{MARCO TEÓRICO}

Neste capítulo são apresentados alguns aspectos conceituais, históricos e relações de interdependência entre Desenvolvimento Sustentável, Turismo e Meio Ambiente. Também, efetua- 
se abordagem sobre a importância de adoção do ecoturismo como modelo de sustentabilidade para o Turismo no país.

\subsection{O Desenvolvimento Sustentável em Evidência}

A origem e entendimento da expressão desenvolvimento sustentável não é clara, pois conforme Bellen (2005) existem diversas interpretações e críticas quanto ao seu significado: "sobre o que deve ser sustentado e tampouco sobre o que o termo sustentar significa" (p. 38). Por longo tempo, desenvolvimento e crescimento foram tratados como sinônimos relativos ao progresso quantitativo das sociedades, provenientes do casamento entre ciência e tecnologia (Veiga, 2008). Difundiu-se a idéia que o desenvolvimento de um povo/nação seria reflexo do crescimento econômico, mensurado e contabilizado por meio de indicadores econômicos (PIB, Renda per capita etc.) capazes de distinguir países pobres de ricos.

Somente no período dos anos de 1960 e 1970, com o ambientalismo, a divulgação de estudos sobre a finitude dos recursos naturais e os debates preparatórios para a Conferência das Nações Unidas sobre o Ambiente Humano de Estocolmo-72, é que floresceu o entendimento da separação e interdependência entre desenvolvimento e crescimento (Pires, 2002; Veiga, 2008). À época, existiam duas posições contraditórias: o Paradigma Social Dominante/PSD e o Ambientalismo Radical. O PSD é formado por um pensamento antropocêntrico defensor do crescimento econômico mundial como prioritário e que defendia o utilitarismo dos recursos produtivos. $\mathrm{O}$ crescimento das nações seria uma conseqüência, pois haveria a devida repartição dos benefícios e conquistas para a sociedade como um todo. A outra perspectiva defendia o ecocentrismo, a harmonia e cooperação entre homem e natureza, cuja prioridade era a redução da pobreza. Havia urgência em estancar o crescimento mundial por meio de limites aos níveis de produção, consumo e poluição, bem como ao crescimento demográfico. Estes fatores poderiam levar a uma situação de exaustão dos recursos naturais e até de risco de extinção da humanidade (Egri \& Pinfield, 2007).

Como alternativa surgiu uma terceira posição, o "caminho do meio" ou Ambientalismo Renovado, que reconhecia a necessidade do crescimento econômico, mediante o emprego de tecnologias para uso racional dos recursos produtivos com menores impactos ambientais. Incorporava a lógica da sustentabilidade em todas as suas dimensões: ecológica, econômica, cultural, ambiental, social, territorial e política (Sachs, 2008). Sustentabilidade integral capaz de abarcar fatores inerentes à satisfação das necessidades de cada ser humano, mas atreladas às necessidades da população como um todo. Em suma, não mais com foco estreito no crescimento racional-quantitativo, mas sim no desenvolvimento como processo de produção de mudanças quantitativas e qualitativas significativas, por meio de preocupações com as condições de vida, saúde, bem-estar, liberdade de escolhas e oportunidades de trabalho, educação e cidadania (Almeida, 2002; Bellen, 2005; Egri \& Pinfield, 2007; Nobre \& Amazonas, 2002; Sen, 1999; Veiga, 2008).

A publicação em 1987 do relatório "Nosso Futuro Comum" pela Comissão Mundial de Meio Ambiente e Desenvolvimento [CMMAD], também conhecida como Comissão Brundtland, marcou a incorporação destas preocupações, pois estabeleceu os moldes para um processo de desenvolvimento dinâmico, harmônico e sustentável entre homem e natureza. O relatório enfatizou a incompatibilidade de manutenção da pobreza, elevou a questão ambiental como parte integrante chave e incluiu o tempo como fator importante quanto às ameaças e oportunidades à sustentabilidade (presente e futura) deste processo (Bellen, 2005).

A definição mais aceita para o termo desenvolvimento sustentável é que este consiste em um processo de transformação em que a "exploração dos recursos, a direção dos investimentos, a orientação do desenvolvimento tecnológico e a mudança institucional se harmonizam e reforçam o potencial presente e futuro, a fim de atender às necessidades e aspirações humanas" (CMMAD, 1991, p. 49). O desenvolvimento sustentável contempla os eixos principais do crescimento

Revista de Gestão Social e Ambiental - RGSA, São Paulo, v. 5, n. 3, p. 116-134, set./dez. 2011. 
econômico, equidade social e equilíbrio/preservação ecológica (Dias, 2008; Donaire, 1999), e interliga dois conceitos-chave: prioridade absoluta em atender as necessidades básicas da população mundial; e compreensão da existência de limites na capacidade ambiental em atender estas necessidades no médio e longo prazo (Dias, 2008). A questão é como fazê-lo um instrumento de ajuste dos rumos da sociedade atual em sua relação com o ambiente natural no longo prazo (Bellen, 2005).

\subsection{Turismo - Aspectos Conceituais e Breve Retrospectiva Histórica}

O turismo é tido como atividade ligada à satisfação de necessidades básicas, como descanso e lazer, que cada vez mais são incorporadas como componentes da qualidade de vida do ser humano (Dias, 2003). Propicia a vivência de sensações e momentos distantes e distintos das preocupações, dos problemas e locais do cotidiano por meio de uma fuga temporária. Consiste em uma atividade peculiar em que se pode consumir um produto sem esgotá-lo e cuja matéria-prima (os recursos turísticos) é intangível, não desaparece pós-consumo permanece do desde que não sofra degradação por uso abusivo ou mal planejado. Em geral, não pode ser extraída ou transformada em produtos comercializáveis a serem consumidos em outras regiões, muito ao contrário, é o consumidor (turista) que vai até o produtor e ao produto turístico (Programa das Nações Unidas para o Meio Ambiente [PNUMA] \& Organização Mundial do Turismo [OMT], 2005). Requer consciência de empresários, turistas, comunidades residentes, trabalhadores, governos etc. de que o ganho advindo da preservação de um atrativo turístico (natural e/ou cultural) pode ser maior e permanente, do que o aferido pela exploração desenfreada e voltada para lucros imediatos (Dias, 2003).

O turismo é um segmento econômico recente, com menos de dois séculos de existência. Em sua origem, era tido como um privilégio das elites ou de poucos aventureiros. Cresceu devido à Revolução Industrial e as melhorias de transporte e comunicação, mas também pela curiosidade e desejo humano de experimentar sensações novas, de descobertas e/ou lazer (Pires, 2002). Ganhou expressão internacional nos idos de 1950, com o 'turismo de massa', caracterizado pelo grande afluxo de pessoas para alguns destinos em períodos de férias escolares e laborais, atraídas por propagandas e pouco sensíveis aos aspectos ecológicos e sócio-culturais dos lugares escolhidos. Segundo Dias (2008), o turismo foi considerado como "uma atividade limpa e não contaminante uma indústria sem chaminé" (p. 13), capaz de gerar benefícios e divisas e de alavancar o crescimento econômico mundial.

Na década de 1970, a realização da Conferência de Estocolmo-72 colocou a dimensão ambiental na agenda mundial (Sachs, 2008). Estudos sobre os impactos negativos (sócioambientais) do 'turismo de massa' e sua capacidade de rápida alteração do meio ambiente modificaram a visão sobre o turismo (Dias, 2008). O crescimento do turismo na Riviera Francesa e Acapulco/México gerou fortes alterações das culturas locais, degradação cênica, destruição ambiental, aumento da prostituição e criminalidade (Oliveira, 2003).

A partir de 1980, o movimento ambientalista estimulou um turismo diferente ou alternativo baseado em uma ética que alinhasse o emergente conceito de sustentabilidade com o respeito as culturas e populações locais, proteção à natureza e enriquecimento da condição humana, em contraposição ao turismo massificado e de larga escala (Pires, 2002). Este turismo alternativo passou a constituir um caminho promissor para se obter melhorias e desenvolvimento, sem dilapidar os recursos naturais do planeta e como fator de conscientização sobre os rumos de um crescimento qualitativo da humanidade. Hoje, é aceito e desejado pela sociedade como padrão a ser estabelecido no turismo mundial, apesar da lógica dominante enfatizar ainda interesses econômicos (Pires, 2002).

Alguns fatos marcantes desta mudança foram: Conferência da OMT em 1980 - refletiu a mudança na relação entre turismo e meio ambiente; Declaração sobre Turismo e Meio Ambiente da Organização das Nações Unidas [ONU] e do PNUMA em 1982 - estabeleceu estes fatores como interdependentes e essenciais ao processo de desenvolvimento humano; adoção da Carta do 
Turismo e do Código do Turista pela OMT em 1985 - explicitou a interligação dos conceitos; Conferência das Nações Unidas sobre Meio Ambiente e Desenvolvimento/Rio-92, originou um plano de ação denominado Agenda 21; e Conferência Mundial de Turismo Sustentável em 1995 originou a Carta de Turismo Sustentável de Lanzarote/Espanha (Dias, 2008; Oliveira, 2003; Pires, 2002).

No século atual, o turismo assume grande importância sócio-econômica como gerador de empregos, devido ao forte crescimento do fluxo de viajantes e da diversificação de suas atividades. Converteu-se em um dos setores econômicos que mais cresce e um dos principais atores do comércio internacional, cerca de $10 \%$ da atividade econômica mundial, e fonte importante de ingressos de divisas de vários países em desenvolvimento. Previsões apontam para a manutenção deste crescimento, e que em 2020, haverá cerca de 1,5 bilhão de chegadas internacionais (Dias, 2008; OMT, 2010; PNUMA \& OMT, 2005).

No Brasil, a atividade do turismo despertou nos anos de 1970, porém bastante desorganizada, carente de planejamento e infra-estrutura adequados. Ganhou impulso nos anos de 1990, devido a(o): consolidação da democracia; abertura da economia; realização da Rio-92; estabilidade monetária com o Plano Real; e ampliação da rede de hospedagem, resorts, parques e empreendimentos de lazer (Beni, 2007).

No presente, o turismo consolida-se como quinta atividade econômica no país (Ministério do Turismo [MTUR], n.d.), devido à: maior concorrência no setor de aviação comercial, melhoria na oferta de destinos, preços e condições de pagamento; do turismo de cabotagem no litoral (cruzeiros marítimos); investimentos em infra-estrutura (aeroportos, portos, estradas, centros de convenções, saneamento básico etc.); criação do Ministério do Turismo, da Secretaria Nacional de Políticas de Turismo e elaboração do Plano Nacional do Turismo/PNT, que realçaram o turismo no contexto político-executivo. Porém, o turismo no país ainda carece de visão sistêmica, holística, de pensamento estratégico e de gestão participativa para alavancar o desenvolvimento nos níveis regional e nacional (Beni, 2007).

O Governo Federal adotou o PNT como um modelo de planejamento quadrienal de gestão pública do turismo, descentralizado e participativo, que estrutura um conjunto de macro-programas e programas alinhados aos Programas e as Ações do Plano Plurianual de Governo. Em sua versão 2007-2010, tem por objetivos: contemplar as diversidades regionais, culturais e naturais; e proporcionar a expansão do mercado turístico interno e da inserção do Brasil no cenário mundial. Assim, visa atrair divisas e incluir o turismo como item de consumo para toda população, com geração de empregos, distribuição de renda, redução das desigualdades sociais e regionais, promoção da igualdade de oportunidades, respeito ao meio ambiente e proteção ao patrimônio histórico e cultural (MTUR, s.d.).

O Brasil pelo tamanho, diversidade de clima, biomas, paisagens, fauna e flora, além da variedade cultural, tem ampla possibilidade para tornar-se exportador de sustentabilidade, capaz de transformar o desafio ambiental em oportunidade e tornar-se um dos pólos mundiais de turismo ligado à natureza (Dias, 2008; Sachs, 2008). Porém, este enorme potencial ainda pouco explorado sofre reflexos do uso indiscriminado de suas riquezas naturais sem estudos devidos de viabilidade. Exemplos podem ser citados referentes a financiamentos públicos em completos turísticos privados (resorts) que não obedeceram aos preceitos estratégicos de desenvolvimento regional e sustentável do turismo (Beni, 2003).

\subsection{Efeitos Econômicos, Sócio-Culturais e Ambientais do Turismo}

Durante décadas o turismo estreitou sua relação com o processo de desenvolvimento, em uma dinâmica que tem convertido este setor em motor chave do progresso sócio-econômico. A atividade do turismo afeta toda a sociedade e gera impactos positivos que contribuem com vários outros setores, devido a(o): alta capacidade de promoção de empregos diretos e indiretos; inclusão social; atração de investimentos públicos e privados; distribuição eqüitativa no nível de vida entre

Revista de Gestão Social e Ambiental - RGSA, São Paulo, v. 5, n. 3, p. 116-134, set./dez. 2011. 
as regiões; melhoria das condições de habitabilidade pela criação de infra-estrutura e equipamentos; estímulo ao desenvolvimento regional etc. (Dias, 2003 e 2008; OMT, 2010).

O turismo de massa, no entanto, ocasiona fortes impactos negativos e custos sócioeconômicos e ambientais aos ecossistemas e às paisagens naturais em todo o planeta (Pires, 2002), em grande parte derivados da falta de um planejamento adequado que gera conseqüências negativas, tais como: desequilíbrio local devido ao fluxo turístico descontínuo; desarticulação e subvalorização das atividades econômicas tradicionais (pesca, artesanato, agricultura de subsistência, pequenas manufaturas etc.); geração de ressentimentos, barreiras ou segregação social pelo encontro de culturas e realidades econômicas diferentes (turista x residente); saturação da infra-estrutura pelo afluxo turístico que altera a vida cotidiana; transformação de valores e condutas morais das comunidades receptoras (drogas, prostituição, trabalho infantil, alcoolismo, comportamentos agressivos); modificação nos padrões de consumo, comportamento e cultura locais (roupas, hábitos, linguajar etc.); transmissão de doenças pelo contato entre turistas e residentes e falta de infra-estrutura de saneamento local; especulação imobiliária e marginalização da população local; impactos no meio natural por contaminação, descaso, destruição e poluição (Dias, 2003; Pires, 2002).

As oportunidades do desenvolvimento do turismo são atraentes, porém sua condução até o presente requer a consideração dos fatores de risco também. É enorme a capacidade do turismo de transformar estruturas territoriais, sociais e urbanas em contextos de modelos de desenvolvimento marcados pela improvisação e pela cultura de curto prazo (Dias, 2003).

\subsection{A Interdependência Entre Turismo e Meio Ambiente}

A relação turismo e meio ambiente sempre foi marcada pela confrontação, pois a atividade turística era vista como consumidora intensiva de espaço e recursos naturais, tanto devido às motivações e interesses do turista (praia, campo, montanha etc.) como pelas alterações ambientais em virtude da infra-estrutura de acesso, alojamentos e equipamentos necessários para sua realização. Contudo, cresce a preocupação com a interdependência entre turismo e preservação ambiental, e com a redução de impactos ambientais, dentro de uma perspectiva que não repita os erros do passado (Dias, 2003 e 2008). O que se pretende é conciliar o uso turístico de um atrativo natural dentro de limites sócio-ambientais aceitáveis e perenes, em oposição ao turismo de massa, depredatório e inconsequente. De maneira que o desenvolvimento econômico e a proteção ambiental não sejam considerados como opostos, mas que se reforcem mutuamente (OMT \& PNUMA, 2005).

$\mathrm{O}$ aumento da consciência ambiental da sociedade tem levado à valorização de práticas de lazer relacionadas com o meio ambiente natural (Dias, 2003), com tendência de crescimento do reencontro com a natureza, de caráter familiar e bem intimista nas relações do turismo com o meio ambiente (Beni, 2003). Torna-se requisito a adoção de práticas sócio-ambientais sustentáveis, de educação e conscientização dos turistas sobre os impactos no meio ambiente, na cultura e nas comunidades dos destinos de lazer e recreação. A opinião pública torna-se mais consciente quanto aos limites da natureza e dos perigos decorrentes das agressões a ela efetuadas (Sachs, 2008), pois cresce a disseminação na mídia sobre os valores ambientais e apelo ao consumo de serviços e produtos positivamente associados estes valores (Pires, 2002). Beni (2003) afirma que "Dificilmente se fará turismo no futuro sem levar em consideração a consagração e a preservação da natureza, pois, afinal, ela é o habitat do ser humano e a garantia de nossa sobrevivência" (p. 65).

Emerge a necessidade de intervenções organizadas e planejadas das atividades de turismo, pois para Sachs (2008) o "planejamento é ferramenta indispensável para projetar e promover estratégias de desenvolvimento sustentável" (p. 56) para alcance da sustentabilidade econômica, sociocultural e ambiental dos espaços locais e nacionais. As ações de governos e empresas do setor requerem foco no desenvolvimento sustentável de longo prazo para garantir proteção e uso racional dos recursos naturais e geração de renda para a população local. O turismo como atividade 
econômica, de interação social e cultural não pode situar-se fora deste processo de integração do homem com a natureza (Dias, 2008).

\subsection{A Necessidade de um Turismo Sustentável}

O Turismo Sustentável consiste naquele: "ecologicamente suportável em longo prazo, economicamente viável, assim como ética e socialmente eqüitativo para as comunidades locais" (OMT, 2010). Esta concepção aponta 3 eixos norteadores do turismo sustentável: o uso suportável dos recursos ambientais, o respeito a autenticidade sócio-cultural das comunidades e a viabilidade econômica de longo prazo que gere benefícios para todos os envolvidos (PNUMA \& OMT, 2005). Consiste de um modelo turístico planejado, integrativo das comunidades e sustentável dos recursos naturais para que estes estejam disponíveis às gerações futuras (Pires, 2002).

O turismo sustentável não deve ser visto como espécie distinta ou especial, mas como condição para todas as formas e práticas turísticas serem mais sustentáveis em si, sobretudo o turismo convencional ou de massa (Pires, 2002). Qualquer forma de turismo gera impactos negativos no ambiente, derivados da presença humana. A tônica é a reorientação do turismo com a incorporação da sustentabilidade, que gere experiências de alta satisfação para o turista, torne-o mais sensível e consciente quanto aos problemas (atuais e futuros), e com isto passe a exigir um turismo mais sustentável e em constante melhoria (PNUMA \& OMT, 2005).

A OMT tem divulgado esta forma de pensamento por todo o segmento do turismo (empresários, comunidades anfitriãs, governos, turistas, ambientalistas e a sociedade), com vistas ao desenvolvimento de um turismo responsável, sustentável e acessível para todos. Isto ocorrerá devido $\mathrm{a}(\mathrm{ao})$ : uso planejado e racional dos recursos naturais de interesse turístico; estímulo ao crescimento econômico; criação de empresas e empregos; incentivo e geração de fontes de renda para a proteção do meio ambiente e do patrimônio dos destinos turísticos; promoção da paz e entendimento mundial (Beni, 2003; OMT, 2010; PNUMA \& OMT, 2005).

Um turismo que não leve em conta a sustentabilidade no longo prazo, pode causar danos e influências negativas ao ambiente, ao bem-estar e a cultura das populações locais, gerar sérios prejuízos aos núcleos turísticos e até a destruição da atividade (Petrocchi, 1998). Os governos exercem papel crucial no estabelecimento das diretrizes para o desenvolvimento e gestão de um turismo mais sustentável, pois o equilíbrio entre a promoção de um produto turístico e a preservação é fundamental. PNUMA e OMT (2005) apontam cinco aspectos para a elaboração de políticas e programas de governo voltados a um turismo sustentável, baseados na interrelação entre as capacidades do turismo de garantir suas condições futuras e da sociedade em absorver e aproveitar seus benefícios: Gestão das pressões exercidas pelo crescimento do turismo internacional que demandará planejamento e gestão adequados da infra-estrutura de suporte; Mudanças climáticas que afetam o turismo e vice-versa; Redução da pobreza, pois o turismo possui grande capacidade para tal; Apoio à conservação ambiental e cultural devido a sua condição de captação e geração de recursos para as comunidades locais; e Saúde e segurança, em que a gestão da informação se torna crucial para reduzir o avanço de doenças e a possibilidade de atentados terroristas.

O Setor do Turismo e os governos necessitam desenvolver políticas de fomento sócioeconômico, como agentes indutores da sustentabilidade mundial. O objetivo da melhoria das condições de vida das populações mediante a redução das desigualdades há que ser perseguido. Isto ocorrerá com a integração de empresários, governos e comunidades locais de modo que, sob as diretrizes e normas estabelecidas pelos órgãos centrais, decidam as prioridades do turismo no desenvolvimento sustentável local e, portanto, quais mecanismos, e ferramentas necessitam ser acionados para alavancar este segmento (Dias, 2003). Uma das principais formas para esta sustentabilidade está no chamado Ecoturismo, modalidade mais condizente ao fomento do papel do turismo na prosperidade e consciência quanto à conservação dos recursos naturais.

\subsection{O ecoturismo como Paradigma de Sustentabilidade do Turismo}

Revista de Gestão Social e Ambiental - RGSA, São Paulo, v. 5, n. 3, p. 116-134, set./dez. 2011. 
O Ecoturismo corresponde a uma das vertentes do turismo alternativo ou de natureza, surgido nos anos de 1990, cujo objetivo é integrar o visitante/turista ao meio ambiente (natural, cultural e social), por meio de atividades esportivas, contemplativas, educativas, científicas, recreativas e até esotéricas e místicas. Dias (2008) afirma que desde que auxiliem na conservação e sustentabilidade da natureza, "pode ser entendido como o turismo sustentável em áreas naturais" (p. 107). É lógico supor, que estas atividades acabam por afetar os recursos naturais e culturais de uma localidade, porém estes são menores que os oriundos do turismo convencional, e aumentam os benefícios auferidos (Pires, 2002 e 2005).

Pires (2002) aponta que existem várias definições e conceitos para o ecoturismo, porém com pontos em comum: ênfase na utilização de áreas naturais, da história e cultura autênticas das comunidades receptoras; minimização de impactos sócio-ambientais e recursos empregados; geração de benefícios e bem-estar para a população anfitriã; compromisso em apoiar o conservacionismo; e disseminação da consciência ecológica via educação ambiental. Caracteriza-se pela busca na natureza da promoção de um turismo de pequena escala, como alternativa de um desenvolvimento caracterizado pelo manejo e conservacionismo ambiental, que segue os princípios do(a): uso sustentável dos recursos; revitalização das economias locais; desenvolvimento planejado e controlado; qualidade de projetos e gestão; integração participativa das comunidades locais.

O delineamento de um produto turístico planejado, com baixos impactos negativos, voltado a um público de maior poder aquisitivo e/ou pesquisadores e acadêmicos, é uma das condições requeridas pelo ecoturismo. Sua ocorrência pode ser em áreas naturais, assim auxilia na conservação destas, via geração de receitas/fundos, além de criar oportunidades locais de trabalho, estimular o associativismo e promover pesquisas científicas e a educação ambiental. Além de estabelecer limites ao número visitantes/dia, com infra-estrutura de reaproveitamento de insumos e com poucos impactos ao ambiente. Capaz de suportar as demandas pelas atividades preferidas deste público (caminhada, estudos, observação, camping etc), mas sem perder a característica de experiência de natureza (Petrocchi, 1998). Contudo, devido ao apelo que a questão ecológicaambiental gera na sociedade, muitos empresários usam o termo para divulgar destinos, produtos ou serviços que não atendem a verdadeira lógica do ecoturismo (Pires, 2002; Soldatelli, 2005).

No Brasil, o Governo Federal a partir de uma Política Nacional de Ecoturismo de 1994, estabeleceu o ecoturismo como grande alternativa ao turismo massificado e padronizado (Dias, 2003 e 2008), cujas diretrizes apontam um caminho com os objetivos de: compatibilizar ecoturismo e conservação de áreas naturais; fortalecer a cooperação interinstitucional; participar de todo o setor do turismo; capacitar o pessoal; criar e melhorar a infra-estrutura do ecoturismo; e tornar o ecoturismo um veículo de educação ambiental.

\section{$3 O$ SNUC E A CONSERVAÇÃO DA NATUREZA NAS RPPNS}

Neste tópico procurou-se abordar a criação, características, objetivos e importância do SNUC para a conservação da natureza no Brasil, bem como caracterizar os tipos e a pertinência de realização de atividades denominadas de Uso Público em Unidades de Conservação (UCs). Por fim, enfatizou-se, em particular, as origens e relevância das RPPNs, como reservas de Domínio Privado, integrantes do SNUC.

\subsection{O Sistema Nacional de Unidades de Conservação da Natureza/SNUC}

A idéia de conservação da natureza tem requerido pensar a manutenção de áreas naturais com pouca ou nenhuma alteração causada pelo homem, ou seja, preservar, manter e recuperar espaços da natureza ou ecossistemas com características de vida selvagem e seus recursos naturais. O marco inicial de tal ordem no mundo foi a criação do Parque Nacional de Yellowstone nos Estados Unidos em 1872. Vários países seguiram esta prática, inclusive o Brasil, cujas primeiras áreas protegidas foram o Parque Estadual de São Paulo em 1896 e o Parque Nacional de Itatiaia em 1937 (Câmara, 2002; Magnanini, 2002).

Revista de Gestão Social e Ambiental - RGSA, São Paulo, v. 5, n. 3, p. 116-134, set./dez. 2011. 
Diversas iniciativas surgiram no país ligadas à proteção de áreas naturais, mas sem definir ou padronizar o que seria uma Unidade de Conservação (UC), fato ocorrido com a Lei Federal n. 9985/2000. Esta lei definiu UC como um espaço territorial protegido, com limites e extensão determinados em lei, em face de características (territoriais, geográficas, geológicas, ecológicas, climáticas, culturais etc.) em que devam ser aplicadas garantias para sua proteção e de seus recursos ambientais (República Federativa do Brasil [BRASIL], 2000).

Este instrumento legal institui o Sistema Nacional de Unidades de Conservação da Natureza/SNUC como uma estratégia de conservação do patrimônio natural e da biodiversidade brasileira. O SNUC é formado pelo conjunto das UCs (federais, estaduais e municipais), que podem ser divididas em dois grupos específicos: Unidades de Proteção Integral - para preservação da natureza, nas quais só é admitido o uso indireto dos seus recursos naturais; e Unidades de Uso Sustentável - nas quais é permitido compatibilizar a conservação da natureza com o uso direto sustentável de parcela de seus recursos naturais, com permissão da visitação pública (BRASIL, 2000; Magnanini, 2002).

Para Câmara (2002) a Lei n. 9985/2000 representou progresso na racionalização da diversidade de atos legais para o estabelecimento de áreas protegidas e consolidou a existência de duas formas de interpretação da natureza: "pelo reconhecimento do valor intrínseco da biodiversidade e pela sua serventia para o homem" (p. 107). Neste entendimento, a lei em BRASIL (2000) define que alguns tipos de UCs podem ter exploração econômica desde que haja garantia de manutenção "dos recursos ambientais renováveis e dos processos ecológicos, mantendo a biodiversidade e os demais atributos ecológicos, de forma socialmente justa e economicamente viável".

As UCs se tornam importantes áreas para o desenvolvimento do ecoturismo no país, assim como este pode consolidar-se em oportunidade de ajuda na melhoria da gestão destas, desde que sejam efetuados planos de manejo e negócios adequados quanto aos impactos na biodiversidade e na capacidade de carga destas unidades, com participação da sociedade civil (Dias, 2008; Pádua, 2002). Desta forma, intenta-se atingir alguns dos objetivos do SNUC que relacionam turismo e conservação da natureza (BRASIL, 2000):

- $\quad$ promover o desenvolvimento sustentável a partir dos recursos naturais;

- $\quad$ promover o uso dos princípios e práticas conservacionistas no desenvolvimento;

- $\quad$ proteger paisagens naturais e pouco alteradas de notável beleza cênica;

- favorecer condições e promover a educação e interpretação ambiental, a recreação em contato com a natureza e o turismo ecológico;

- proteger os recursos naturais necessários à subsistência de populações tradicionais, com respeito e valorização de seu conhecimento e cultura, e promoção sócio-econômica.

Entretanto, cabe alerta quanto a proliferação excessiva de UCs, pois muitas são criadas sem os devidos cuidados com suas verdadeiras finalidades de preservação das belezas cênicas, proteção dos recursos hídricos, manejo dos recursos naturais, desenvolvimento de pesquisas, manutenção do equilíbrio climático e ecológico (Milano, 2005), enfim conservação da biodiversidade (Pádua, 2002). Unidades que existem mais no papel, para atender interesses políticos-eleitoreiros ou justificar alguma atuação em prol do meio ambiente, do que na realidade. Na prática as UCs carecem de estudos sobre viabilidade financeira, condições de implantação, planos de manejo, ocupação das áreas, regularização fundiária, fiscalização, pressões das comunidades circunvizinhas, quantidade e capacitação de pessoal e até sobre qual a devida categoria que deve ser classificada (Câmara, 2004; Hauff, 2004; Pádua, 2002). Estas unidades tornam-se vulneráveis, entendidas por Pádua (2002) como "terras de ninguém" (p. 4). Mesmo assim, Câmara (2004) defende a criação de áreas de proteção (UCs) como melhor opção, senão a única para proteger e preservar a natureza, com redução no ritmo de extinção de espécies ocasionadas pelas atividades humanas. Milano (2005) afirma que "deve-se proteger a natureza através de espaços territoriais especificamente

Revista de Gestão Social e Ambiental - RGSA, São Paulo, v. 5, n. 3, p. 116-134, set./dez. 2011. 
identificados e definidos contra as ações destrutivas do homem, ainda que para o benefício dele próprio" (p. 204).

\subsection{Uso Público em Unidades de Conservação (UCs)}

O uso produtivo das UCs pode existir, pois não precisa ser prejudicial ou destruir o meio ambiente, basta que ocorra consciência que as atividades econômicas são baseadas no ambiente natural, pois Sachs (2008) defende que "Conservação e aproveitamento racional da natureza podem e devem andar juntos" (p. 32). Câmara (2004) aponta que esta é uma tendência ligada ao "novo paradigma' das áreas protegidas e efetua críticas quanto a abordagem que privilegia mais os aspectos sócio-econômicos (curto-prazo) em detrimento da conservação da natureza (longo prazo), mas alude que os interesses das comunidades locais devem ser atendidos desde que compatíveis com os objetivos da conservação. Hauff (2004) efetua crítica as administrações de UCs por executarem ações com foco na melhoria das condições das comunidades do entorno e que geram às vezes descuido em suas responsabilidades para com a conservação ambiental.

O uso público corresponde à realização de atividades de turismo, pesquisa e/ou de educação ambiental, atividades que possuem peculiaridades, mas que não impedem sua realização conjunta. Torna-se interessante alternativa produtiva, desde que compatível com os objetivos da categoria da UC em questão e contemplado em seu plano de manejo. Pode-se supor que a implantação de tais atividades, sob rígido controle de seus impactos, possa potencializar a conservação do meio ambiente com o desenvolvimento do potencial turístico local, capaz de gerar um usufruto consciente e educacional da natureza (Hauff, 2004).

Para Dias (2008) as atividades de turismo em UCs potencializam tanto a educação ambiental e estimulam o interesse por pesquisas sobre a natureza e seus componentes, pois "não é possível pensar em ecoturismo sem pensar em educação ambiental" (p. 178). Aspectos relativos à redução do consumo de recursos naturais, reciclagem de resíduos, valorização do entorno paisagístico e proteção da biodiversidade, são incluídos na prática do ecoturismo para os visitantes/turistas, como também para a população receptora e todos os envolvidos na atividade. Isto possibilita oportunidade de desenvolver a consciência ecológica e cultural e a organização da coletividade na participação e defesa da qualidade do meio ambiente, manifestada em posturas e atitudes diante do ambiente e da sociedade (Pires, 2005).

O turismo tem por base de sustentação a natureza, assim às áreas naturais protegidas podem ser importantes atrações turísticas, bem como estas incentivam a criação de novas áreas e reforçam a relevância da participação de cada cidadão (turista ou residente) quanto à preservação da natureza. Quando as atividades turísticas são ordenadas e planejadas, podem maximizar os benefícios econômicos e oportunidades de trabalho para a população e os recursos para conservação ambiental (Dias, 2008; Hauff, 2004; Petrocchi, 1998).

Existem reações contrárias ao uso turístico dos recursos naturais, sobretudo nas áreas de proteção ambiental, em que especial cuidado deve ser dado aos possíveis excessos cometidos nestas áreas (Câmara, 2004), mas face aos problemas sociais do país, seu uso é recomendável (Petrocchi, 1998). Todavia, a capacidade de suporte deve ser considerada, pois uma UC não pode receber todos que queiram admirá-la; torna-se necessário impor limites ao número de visitantes e aos locais de acesso e uso, da mesma forma como deve ocorrer para qualquer outro atrativo turístico natural (Dias, 2003). São necessários estudos efetivos sobre a adequação da demanda de uma oferta turística (Braga, 2003) e a adoção de políticas conciliatórias que permitam o crescimento gradativo e sustentável do turismo em aliança com a natureza, sem comprometer a biodiversidade, que respeite a capacidade de carga e os planos de manejo elaborados (Beni, 2003; Soldatelli, 2005).

Cabe destacar a significativa participação das Organizações Não-Governamentais (ONGs), que auxiliam na viabilização de financiamentos e assistência técnica a projetos de ecoturismo, e nas negociações com os diferentes atores (Pires, 2005). Para Pádua (2002), no Brasil as UCs que

Revista de Gestão Social e Ambiental - RGSA, São Paulo, v. 5, n. 3, p. 116-134, set./dez. 2011. 
possuem parcerias de co-gestão e desenvolvimento de projetos com ONGS são as que possuem melhores condições de manejo.

\subsection{RPPNs: Unidades de Conservação de Domínio Privado}

As RPPNs constituem espaços naturais de proteção da biodiversidade, mediante livre manifestação e vontade do(s) proprietário(s), sem ocasionar perda do direito de propriedade (Instituto Chico Mendes de Conservação da Biodiversidade [ICMBIO], 2010). A iniciativa privada assume responsabilidades de governança em áreas de conservação ambiental: proteger a diversidade biológica; preservar paisagens de grande beleza; e promover a conservação de ecossistemas frágeis ou ameaçados.

Sua origem remonta as chamadas "florestas protetoras" previstas no antigo Código Florestal (Decreto $\mathrm{n}^{\mathrm{o}} 23.793 / 1934$ ), constituídas como áreas particulares protegidas e que permaneceriam de posse e domínio de seu(s) proprietário(s), mas inalienáveis. Com a evolução da legislação e regulamentação sobre as áreas protegidas no país, a figura das florestas protetoras deixou de existir. Foram criados os Refúgios Particulares de Animais Nativos/REPANs em 1977, renomeados para Reservas Particulares de Fauna e Flora em 1988. Somente em 1990, com o Decreto Federal $\mathrm{n}^{\circ}$ 98.914, é que o nome e a forma atual destas reservas foram definidos (Ministério do Meio Ambiente [MMA] \& ICMBIO, 2007).

O Governo Federal ao instituir o SNUC em 2000, definiu as RPPNs como Unidades de Uso Sustentável, de domínio privado, perpétuas, com o objetivo de conservação da diversidade biológica, voltadas para os fins de pesquisas científicas e de visitação com objetivos turísticos, recreativos e educacionais, conforme previstos no Termo de Compromisso e no plano de manejo. Em 2006, foram estabelecidos critérios e procedimentos administrativos referentes à criação de RPPNs (Instituto Brasileiro do Meio Ambiente e dos Recursos Naturais Renováveis [IBAMA], 2005; MMA \& ICMBIO, 2007).

De acordo com o ICMBIO (2010), as RPPNs são importantes por: contribuírem para a rápida ampliação das áreas protegidas no país; apresentarem índices positivos na relação custo/benefício; serem de fácil criação; possibilitarem a participação da iniciativa privada no esforço nacional de conservação; e contribuírem para a proteção da biodiversidade dos biomas. Câmara (2002) reforça esta idéia das RPPNs como efetivas participantes no processo de conservação da diversidade, apesar de serem em sua maioria constituídas de áreas reduzidas, fato que não auxilia na viabilidade genética de muitas espécies no longo prazo. Estas iniciativas privadas espontâneas tem tido crescente adesão por todo o país, com aumento na conscientização da população quanto à importância de proteger a natureza.

\section{ESTADO ATUAL, DISTRIBUIÇÃO E USO PÚBLICO NAS RPPNS}

Neste capítulo efetuou-se um levantamento sobre a situação das RPPNs no País, a partir de dados secundários, com apresentação da distribuição territorial quanto aos aspectos geo-políticos (por região e estado) e biofísicos (por bioma), além da caracterização da forma de propriedade (pessoa jurídica ou física). Efetuou-se a identificação de RPPNs que desenvolvem atividades de uso público e a especificação do tipo destas atividades.

\subsection{Situação Atual das RPPNs e Distribuição no País}

Para fins de apresentação do estado atual e atividades de uso público desenvolvidas em RPPNs, foram efetuadas pesquisas nos seguintes sites institucionais:

- IBAMA, órgão federal ligado ao Ministério do Meio Ambiente. Apresenta relatórios com informações de um total de 425 RPPNs autorizadas até dezembro/2005, com área de 442.853,46

Revista de Gestão Social e Ambiental - RGSA, São Paulo, v. 5, n. 3, p. 116-134, set./dez. 2011. 
hectares (ha), em que constam: Nome da Reserva, Município, UF, Área da Reserva, Portaria de Autorização e Nome do Proprietário (IBAMA, 2005);

- ICMBIO, autarquia ligada ao IBAMA e que desde 2007 passou a ser responsável por administrar as UCs federais, e executar as ações da política nacional de unidades de conservação. Dentre suas funções estão: executar as políticas de uso sustentável dos recursos naturais renováveis e de apoio ao extrativismo e às populações tradicionais nas UCs federais de uso sustentável; monitorar o uso público e a exploração econômica dos recursos naturais nas unidades de conservação onde isso for permitido, obedecidas as exigências legais e de sustentabilidade do meio ambiente. Apresenta o mesmo relatório que o IBAMA, porém com dados mais atuais (fevereiro/2010), com um número total de 539 RPPNs autorizadas legalmente no país e área total de 487.852,10 ha (ICMBIO, 2010);

- CNRPPN, associação civil sem fins econômicos, fundada em 2001, representativa das associações de RPPNs. Possui como objetivos: defender e preservar o meio ambiente; representar, integrar, buscar e promover o reconhecimento e benefícios das RPPN; promover e incentivar a conservação da biodiversidade e o ecoturismo no país. Apresenta que existem 931 RPPNs (até abril/2010), com área total de 672.871,13 ha (CNRPPN, 2010).

Para uma visão mais abrangente e atualizada neste estudo, optou-se pelo uso das informações disponibilizadas pela CNRPPN, que mostram a distribuição territorial das reservas por região, estado e bioma do país, bem como o tipo de propriedade (jurídica ou física), e permitiram elaborar a Figura 1 e as Tabelas 1 e 2.

Tabela 1: Distribuição de RPPNs por estado e região.

\begin{tabular}{|c|c|c|c|c|c|c|c|}
\hline \multirow{2}{*}{ ESTADO/REGIÃO } & \multicolumn{3}{|c|}{ PROPRIETÁRIO } & \multicolumn{2}{|c|}{ TOTAL DE RPPNs } & \multicolumn{2}{|c|}{ ÁREA TOTAL } \\
\hline & $\mathbf{P F}$ & PJ & NI & (Und) & $(\%)$ & (Ha) & $(\%)$ \\
\hline Espírito Santo & 3 & 11 & 0 & 14 & 1,50 & $3.595,24$ & 0,53 \\
\hline Minas Gerais & 80 & 138 & 0 & 218 & 23,42 & $124.335,92$ & 18,48 \\
\hline Rio de Janeiro & 18 & 59 & 3 & 80 & 8,59 & $6.148,75$ & 0,91 \\
\hline São Paulo & 13 & 33 & 0 & 46 & 4,94 & $6.781,12$ & 1,01 \\
\hline SUDESTE & 114 & 241 & 3 & 358 & 38,45 & $140.861,03$ & 20,93 \\
\hline Paraná & 27 & 187 & 0 & 214 & 22,99 & $50.200,76$ & 7,46 \\
\hline Rio Grande do Sul & 2 & 24 & 0 & 26 & 2,79 & $4.086,35$ & 0,61 \\
\hline Santa Catarina & 7 & 23 & 0 & 30 & 3,22 & $16.417,05$ & 2,44 \\
\hline SUL & 36 & 134 & $\mathbf{0}$ & 270 & 29,00 & $70.704,16$ & 10,51 \\
\hline Distrito Federal & 1 & 3 & 0 & 4 & 0,43 & 138,22 & 0,02 \\
\hline Goiás & 10 & 37 & 0 & 47 & 5,05 & $32.308,85$ & 4,80 \\
\hline Mato Grosso & 7 & 8 & 0 & 15 & 1,61 & $172.980,67$ & 25,71 \\
\hline Mato Grosso do Sul & 17 & 25 & 0 & 42 & 4,51 & $134.236,83$ & 19,95 \\
\hline CENTRO-OESTE & 35 & 73 & 0 & 108 & 11,60 & $\mathbf{3 3 9 . 6 6 4 , 5 7}$ & $\mathbf{5 0 , 4 8}$ \\
\hline Alagoas & 3 & 9 & 1 & 13 & 1,40 & 938,91 & 0,14 \\
\hline Bahia & 12 & 63 & 0 & 75 & 8,06 & $38.028,09$ & 5,65 \\
\hline Ceará & 6 & 11 & 0 & 17 & 1,83 & $11.915,37$ & 1,77 \\
\hline Maranhão & 5 & 6 & 0 & 11 & 1,18 & $3.738,27$ & 0,56 \\
\hline Paraíba & 2 & 6 & 0 & 8 & 0,86 & $6.652,62$ & 0,99 \\
\hline Pernambuco & 4 & 11 & 3 & 18 & 1,93 & $4.161,99$ & 0,62 \\
\hline Piauí & 0 & 7 & 0 & 7 & 0,75 & $33.929,47$ & 5,04 \\
\hline Rio Grande do Norte & 2 & 2 & 0 & 4 & 0,43 & $2.971,80$ & 0,44 \\
\hline Sergipe & 0 & 3 & 0 & 3 & 0,32 & 484,58 & 0,07 \\
\hline NORDESTE & 34 & 118 & 4 & 156 & 16,76 & $102.821,10$ & 15,28 \\
\hline Acre & 1 & 0 & 0 & 1 & 0,11 & 38,01 & 0,01 \\
\hline Amapá & 1 & 4 & 0 & 5 & 0,54 & $10.113,97$ & 1,50 \\
\hline Amazonas & 3 & 11 & 0 & 14 & 1,50 & 614,86 & 0,09 \\
\hline Pará & 2 & 3 & 0 & 5 & 0,54 & $2.829,00$ & 0,42 \\
\hline Rondônia & 1 & 4 & 0 & 5 & 0,54 & $2.713,06$ & 0,40 \\
\hline Roraima & 1 & 2 & 0 & 3 & 0,32 & $1.047,54$ & 0,16 \\
\hline Tocantins & 1 & 4 & 1 & 6 & 0,64 & $1.463,83$ & 0,22 \\
\hline
\end{tabular}

Revista de Gestão Social e Ambiental - RGSA, São Paulo, v. 5, n. 3, p. 116-134, set./dez. 2011. 


\begin{tabular}{|l|c|c|c|c|c|r|r|}
\hline NORTE & 10 & 28 & 1 & 39 & 4,19 & $18.820,27$ & 2,80 \\
\hline TOTAL & 229 & 694 & 8 & 931 & $\mathbf{1 0 0 , 0 0}$ & $\mathbf{6 7 2 . 8 7 1 , 1 3}$ & 100,00 \\
\hline
\end{tabular}

Legenda: PF = Pessoa Física; PJ = Pessoa Jurídica; NI = Não Informado; Ha = Hectare

Fonte: Adaptado de CNRRPN (2010).

A análise relacionada da Tabela 1 com a Figura 1, mostra a distribuição das RPPNs por estados e regiões geopolíticas do país, com informações sobre quantidade, área, tipo de proprietários e permite as seguintes constatações:

- as regiões Sudeste e Sul concentram dois terços das RPPNs do país $(67,45 \%)$, porém somam menos de um terço da área total destas reservas $(31,44 \%)$;

- o Centro-Oeste é a quarta região em número de reservas $(11,60 \%)$, porém concentra mais da metade da área total $(50,48 \%)$ de RPPNs;

- o Norte é a região com menor número de reservas $(4,19 \%)$ e área total $(2,80 \%)$;

- Minas Gerais (218) e Paraná (214) concentram quase a metade das RPPNs $(46,40 \%)$, seguidos por Rio de Janeiro (80) e Bahia (75);

- Mato Grosso e Mato Grosso do Sul respondem por quase metade da área total das destas reservas (45,66\%), seguidos por Minas Gerais $(18,48 \%)$ e Paraná $(7,46 \%)$;

- o Rio de Janeiro concentra menos de $1 \%$ da área do total de RPPNs no país;

- quase $75 \%$ das reservas são de propriedade de Pessoas Jurídicas.

Figura 1: Comparação percentual por regiões entre o número de RPPNs e área total.

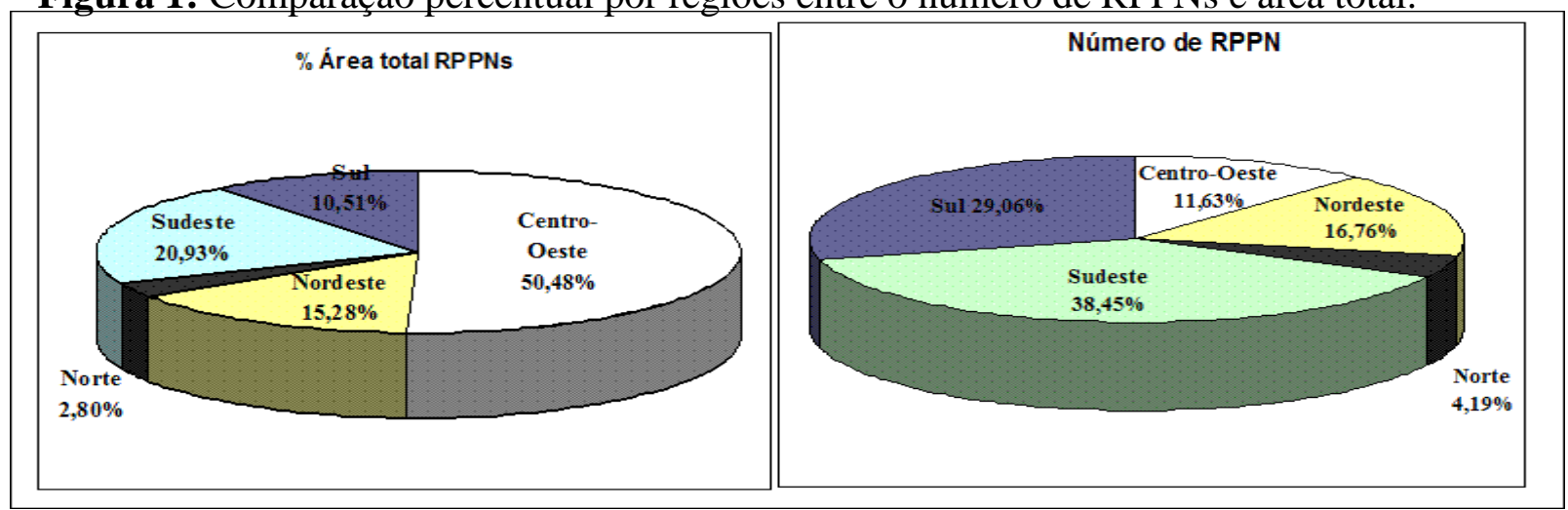

Fonte: Adaptado de CNRRPN (2010).

A Tabela 2 apresenta a distribuição de RPPNs pelos diversos Biomas do país, com dados sobre quantidade e áreas ocupadas. Sua análise permite identificar: a Mata Atlântica é o maior bioma em número de RPPNs $(66,49 \%)$, porém terceiro em área total $(19,34 \%)$; no Pantanal existem só 22 unidades $(2,36 \%)$, mas que ocupam cerca de $40 \%$ da área conservada por RPPNs no país; o Cerrado é o segundo maior bioma em número de RPPNs (182) e em área ocupada (23,75\%); os biomas Marinho-Costeiro e Pampa-Campos Sulinos possuem cerca de 2\% do número (19 no total) com $0,67 \%$ da área total de RPPNs no país.

Tabela 2: Distribuição de RPPNs por Bioma

\begin{tabular}{|l|c|c|c|c|}
\hline \multicolumn{1}{|c|}{ Bioma } & $\begin{array}{c}\text { No. de } \\
\text { RPPN }\end{array}$ & $\begin{array}{c}\text { Total de RPPNs } \\
(\mathbf{\%})\end{array}$ & Área (ha) & Área total (\%) \\
\hline Amazônia & 42 & 4,51 & $39.418,98$ & 5,86 \\
\hline Caatinga & 47 & 5,05 & $75.891,98$ & 11,28 \\
\hline Cerrado & 182 & 19,55 & $159.760,05$ & 23,75 \\
\hline Marinho/Costeiro & 11 & 1,18 & $1.372,71$ & 0,20 \\
\hline Mata Atlântica & $\mathbf{6 1 9}$ & $\mathbf{6 6 , 4 9}$ & $130.139,06$ & 19,34 \\
\hline Pampa/Campos Sulinos & 8 & 0,86 & $3.169,66$ & 0,47 \\
\hline
\end{tabular}

Revista de Gestão Social e Ambiental - RGSA, São Paulo, v. 5, n. 3, p. 116-134, set./dez. 2011. 
Uso público nas reservas particulares do patrimônio natural - convergência entre turismo e conservação ambiental no Brasil

\begin{tabular}{|l|c|c|c|c|}
\hline Pantanal & 22 & 2,36 & $\mathbf{2 6 3 . 1 1 8 , 6 9}$ & $\mathbf{3 9 , 1 0}$ \\
\hline TOTAL & $\mathbf{9 3 1}$ & $\mathbf{1 0 0 , 0 0}$ & $\mathbf{6 7 2 . 8 7 1 , 1 3}$ & $\mathbf{1 0 0 , 0 0}$ \\
\hline
\end{tabular}

Fonte: Adaptado de CNRRPN (2010).

A constatações referentes à análise em conjunto da Figura 1 e Tabelas 1 e 2, foram:

- as RPPNs têm participação efetiva no processo de conservação da bio-diversidade, com presença em todos os estados e biomas do país e área total de mais de 670 mil ha;

- os biomas da Mata Atlântica e Cerrado concentram 86,04\% das RPPNs no país. As RPPNs se concentram nos estados de Minas Gerais (Sudeste), Paraná (Sul), Rio de Janeiro (Sudeste) e Bahia (Nordeste) que somam 587 reservas $(63,19 \%$ do total do país). Isto pode estar relacionado a forte ocupação histórica destes biomas, que gerou adensamento populacional e grande destruição devido às atividades de extrativismo vegetal e mineral, agrícolas intensivas (monoculturas), pecuária extensiva e especulação territorial. Contudo, nos últimos anos tem ocorrido boa divulgação na mídia, além do surgimento de ONGs e melhorias na legislação que visam estimular e incentivar a conservação do que resta destes biomas naturais, assim tem aumentado o número de RPPNS;

- os estados de Mato Grosso e Mato Grosso do Sul (região Centro-Oeste) possui 22 unidades, com área média de 11.959,64 ha, o que leva o bioma do Pantanal a responder pela maior área de cobertura de RPPNs no país $(39,13 \%)$. Isto pode ser explicado por ser uma área de ocupação recente e pouco adensamento populacional, o que gera crescente interesse de estudo da biodiversidade local e da exploração de seu potencial turístico natural. Outra consideração é quanto a existência de grandes áreas alagadiças que inviabilizaram por muito tempo as atividades de extrativismo e agricultura extensiva, fato que gerou pouca pressão antrópica, com amortecimento da especulação territorial e do interesse mercantil pela terra;

- o bioma Amazônico característico da região Norte, teve pouca ocupação populacional apesar de sua grande extensão total. Possui menos de 5\% das RPPNs do país, com maior concentração no estado do Amazonas. Cabe destacar que no Acre somente existe uma RPPN. A área média das unidades no bioma é de 938,55 ha, porém dois terços não passam de 100 ha. Cabe realçar que este bioma possui enormes áreas inexploradas a serem estudadas por sua rica biodiversidade, mas sofre com o extrativismo descontrolado (animal, vegetal e mineral), além do desmatamento para exploração madeireira e ocupação pecuária;

- o bioma Marinho-Costeiro possui 11 RPPNs no total, com pouco mais de 1.300 ha, apesar de presença em quase todas as regiões do país. Este bioma requer atenção devido as fortes pressões exercidas pelas atividades de pesca artesanal e industrial e pelo aumento dos níveis de poluição dos estuários dos rios que deságuam no Oceano Atlântico;

- o bioma Pampa-Campos Sulinos concentra-se no estado do Rio Grande do Sul, possui 8 RPPNs com área aproximada de 3.200 ha e está sujeito às pressões oriundas da agro-pecuária extensiva e caça ilegal.

\subsection{RPPNs com Atividades de Uso Público}

A CNRPPN (2010) disponibiliza informações básicas sobre as RPPNs no país, tais como: nome da reserva e do proprietário, Município/Estado/Região, área da reserva, ano de criação e bioma a que pertence. Para complementar estas informações, a CNRPPN solicitou aos proprietários ou responsáveis legais pelas reservas que incluíssem dados sobre a realização de atividades de uso público: ecoturismo; educação ambiental; fomento a interação social e apoio à pesquisa. Pelas informações declaradas pelos proprietários/responsáveis (CNRPPN, 2010) foram identificadas 37 RPPNs que desenvolvem atividades de uso público (Tabela 3), cuja especificação do tipo de atividades desenvolvidas encontra-se na Tabela 4.

Tabela 3: RPPNs que realizam atividades de uso público

\begin{tabular}{|l|l|l|l|l}
$\mathbf{N}$ & Nome & Município/Estado & Área (ha) & Bioma
\end{tabular}

Revista de Gestão Social e Ambiental - RGSA, São Paulo, v. 5, n. 3, p. 116-134, set./dez. 2011. 


\begin{tabular}{|c|c|c|c|c|}
\hline 1 & Ambientalista Francy Nunes & General Sampaio - CE & 200.00 & Caatinga \\
\hline 2 & Ararauna & $\mathrm{Uma} / \mathrm{BA}$ & 39.00 & Mata Atlântica \\
\hline 3 & Cabeceira do Prata & Jardim/MS & 307.53 & Cerrado \\
\hline 4 & Corredor do Iguaçu & Nova Laranjeiras/PR & 5151.00 & Mata Atlântica \\
\hline 5 & Ecoparque de Una & $\mathrm{Uma} / \mathrm{BA}$ & 83.28 & Mata Atlântica \\
\hline 6 & Elias Andrade & General Sampaio - CE & 207.92 & Caatinga \\
\hline 7 & Encantos da Juréia & Pedro de Toledo/SP & 16.04 & Mata Atlântica \\
\hline 8 & Estação Veracel & Porto Seguro/BA & 6069.00 & Mata Atlântica \\
\hline 9 & Estadual Fazenda Legendária & Laranjal/PR & 50.00 & Mata Atlântica \\
\hline 10 & Estadual Mata Suiça II & Lunardelli/PR & 645.00 & Mata Atlântica \\
\hline 11 & Estância Manacá & Ibicaraí/BA & 95.00 & Mata Atlântica \\
\hline 12 & Fazenda Barbacena & São Pedro do Ivaí/PR & 554.80 & Mata Atlântica \\
\hline 13 & Fazenda Bulcão & Aimorés/MG & 608.69 & Mata Atlântica \\
\hline 14 & Fazenda Lagoa & Monte Belo - MG & 291.56 & Mata Atlântica \\
\hline 15 & Fazenda Pantanal & Codó/MA & 40.76 & Cerrado \\
\hline 16 & Fazenda Placas & Paripueira/AL & 202.33 & Mata Atlântica \\
\hline 17 & Fazenda São Pedro & Pilar/AL & 50.00 & Mata Atlântica \\
\hline 18 & Fazenda Tocaia & Santana do Ipanema/AL & 21.70 & Caatinga \\
\hline 19 & Jardim das Delícias & Nova Friburgo/RJ & 20.43 & Mata Atlântica \\
\hline 20 & Mãe da Mata & Ilhéus/BA & 13.36 & Mata Atlântica \\
\hline 21 & Ninho do Corvo & Prudentópolis/PR & 10.59 & Mata Atlântica \\
\hline 22 & $\begin{array}{l}\text { Quedas do Sebuí/ Reserva } \\
\text { Ecológica do Sebuí }\end{array}$ & Guaraqueçaba/PR & 400.78 & Mata Atlântica \\
\hline 23 & Rancho Mira-serra & São Francisco de Paula/RS & 17.68 & Mata Atlântica \\
\hline 24 & Recanto da Serra Negra & Piracuruca/PI & 179.15 & Caatinga \\
\hline 25 & Reserva El Nagual & Magé/RJ & 17.20 & Mata Atlântica \\
\hline 26 & Reserva Natural Salto Morato & Guaraqueçaba/PR & 819.18 & Mata Atlântica \\
\hline 27 & Reserva Salto Apepique & Ilhéus/BA & 118.00 & Mata Atlântica \\
\hline 28 & Rio das Lontras & São Pedro de Alcântara/SC & 20.00 & Mata Atlântica \\
\hline 29 & Santuário Rã-Bugio I & Guaramirim/SC & 1.89 & Mata Atlântica \\
\hline 30 & Santuário Rã-Bugio II & Guaramirim/SC & 2.75 & Mata Atlântica \\
\hline 31 & Serra das Almas & Crateús/CE & 4749.58 & Caatinga \\
\hline 32 & Serra do Pitoco & Atalanta/SC & 3.00 & Mata Atlântica \\
\hline 33 & Serra do Tombador & Cavalcante/GO & 8730.45 & Cerrado \\
\hline 34 & Sítio do Zaca & Ipatinga/MG & 17.34 & Mata Atlântica \\
\hline 35 & Sítio Serra do Tigre & Ivaí/PR & 7.26 & Mata Atlântica \\
\hline 36 & Slomp & Campo Mourão/PR & 27.42 & Mata Atlântica \\
\hline 37 & Vale das Araras & Cavalcante/GO & 31.75 & Cerrado \\
\hline
\end{tabular}

Fonte: Dados compilados pelos autores.

A Tabela 3 permite observar que a maioria das reservas está nas regiões Sul (14) e Nordeste (12), com incidência nos estados do Paraná (9), Bahia (6) e Santa Catarina (4). Em relação ao bioma, predomina Mata atlântica (28) e em seguida somente Caatinga (5) e Cerrado (4). Estas reservas constituem $4,43 \%$ da área total de RPPNs no país (29.821,42 ha).

O número de RPPNs identificado com certeza não expressa a totalidade de reservas que possuem atividades de uso público, pois muitos responsáveis não completaram o cadastro de informações requeridas. Contudo, os dados de CNRPPN podem ser considerados significativos por exemplificarem a interligação entre conservação ambiental e uso público neste tipo de reserva. Importante destacar que foram identificadas 7 reservas com os 4 tipos de atividades de uso público: Encantos da Juréia; Fazenda Barbacena; Rancho Mira-serra; Reserva El Nagual; Reserva Natural Salto Morato; Rio das Lontras; e Serra das Almas 
Tabela 4: Atividades de Uso Público nas RPPNs

\begin{tabular}{|c|c|c|c|}
\hline USO PÚBLICO & ATIVIDADE & N RPPNS & $\%$ \\
\hline \multirow{4}{*}{$\begin{array}{l}\text { Ecoturismo } \\
28 \text { RPPNs }\end{array}$} & Abertura a visitação pública & 28 & 100,00 \\
\hline & Cobrança de taxa de visitação & 14 & 50,00 \\
\hline & Existência de Centro de visitação & 12 & 42,86 \\
\hline & Disponibilidade de Hospedagem /alimentação & 10 & 35,71 \\
\hline \multirow{6}{*}{$\begin{array}{c}\text { Educação Ambiental } \\
26 \text { RPPNs }\end{array}$} & Realização de visitas de estudantes & 23 & 88,46 \\
\hline & Programa de Capacitação ambiental & 12 & 46,15 \\
\hline & Programa de Estágio em Educação Ambiental & 11 & 42,31 \\
\hline & Distribuição de Material Didático & 8 & 30,77 \\
\hline & Existência de Biblioteca & 7 & 26,92 \\
\hline & Programa de Voluntariado & 7 & 26,92 \\
\hline \multirow{3}{*}{$\begin{array}{c}\text { Fomento à interação social } \\
13 \text { RPPNs }\end{array}$} & Atividades Sustentáveis & 11 & 84,62 \\
\hline & Agroecologia & 6 & 46,15 \\
\hline & Artesanato Local & 5 & 38,46 \\
\hline \multirow{11}{*}{$\begin{array}{c}\text { Pesquisa Científica } \\
\text { (participação em projetos) } \\
12 \text { RPPNs }\end{array}$} & Existência de estrutura de apoio à pesquisa & 11 & 91,67 \\
\hline & Biodiversidade & 8 & 66,67 \\
\hline & Espécies invasoras & 7 & 58,33 \\
\hline & Valorização Econômica dos Recursos Naturais & 7 & 58,33 \\
\hline & Ecologia de Espécies & 6 & 50,00 \\
\hline & Recursos Hídricos & 6 & 50,00 \\
\hline & Educação Ambiental & 6 & 50,00 \\
\hline & Hidrologia & 6 & 50,00 \\
\hline & Restauração Florestal & 5 & 41,67 \\
\hline & Geologia & 4 & 33,33 \\
\hline & Liminologia & 3 & 25,00 \\
\hline
\end{tabular}

Fonte: Dados compilados pelos autores.

A Tabela 4 mostra que a principal prática de uso público em $28(75,68 \%)$ das RPPNs identificadas é o Ecoturismo, com as atividades de 'Abertura a visitação pública' em todas e 'Cobrança de taxa de visitação' em metade delas. Em seguida, aparece a prática de Educação Ambiental (70,27\%), por meio da atividade principal de 'Realização de visitas de estudantes' em quase todas. O Fomento à Interação Social aparece a seguir $(35,14 \%)$, com destaque para as 'Atividades Sustentáveis'. Por fim, aparece a Pesquisa Científica em quase um terço das reservas $(32,43 \%)$, com foco em atividades de 'Existência de estrutura de apoio à pesquisa' em quase todas, e estudo da 'Biodiversidade', 'Espécies Invasoras' e 'Valorização Econômica dos Recursos Naturais'.

\section{CONSIDERAÇÕES FINAIS}

Este trabalho consistiu da análise exploratória sobre o estado atual das RPPNs e da identificação da ocorrência de atividades de uso público (ecoturismo, pesquisa e/ou de educação ambiental, bem como o fomento à interação social das comunidades de entorno) nestas reservas/UCs. Observou-se que é possível conciliar as atividades de conservação da natureza e de turismo, que são cada vez mais requeridas e cobradas pela sociedade. Estas atividades podem ser compatíveis e complementares desde que se respeitem os princípios e as diretrizes do desenvolvimento sustentável, e que assim surtirão efeitos muito mais positivos e mútuos. $\mathrm{O}$ turismo 
quando planejado e organizado com vistas sua utilidade econômica e perenidade, pode se valer das UCs para desenvolvimento das práticas de ecoturismo, aliadas a educação ambiental e a melhoria de renda e condições de trabalho local para as comunidades mais fragilizadas e isoladas dos grandes centros urbanos. De outra feita, as UCs podem obter com isso fontes de recursos, via cobrança de taxas de acesso, hospedagem, passeios etc., que proporcionam condições para melhor remuneração e capacitação de funcionários, construção de estruturas receptivas que facilitem a realização de pesquisas e, ainda, regularizar e implementar seu funcionamento de fato em prol da manutenção da biodiversidade.

No entanto, a interligação entre as atividades de turismo e conservação requer a realização de estudos quanto ao dimensionamento, características, frequência e tipo de interação dos visitantes que sejam mais adequadas às condições das áreas naturais, com vista a minimizar os impactos na flora, fauna, solos, ar, recursos hídricos e estéticos das paisagens, bem como, nas variações de seus ciclos de vida, tempo e clima. Assim, como que seja capaz de conciliar e harmonizar os interesses de todos os participantes: turistas, populações residentes, trabalhadores, empresários, governos e sociedade como um todo.

As RPPNs consistem em uma categoria de UCs com amplas condições para auxiliar neste imbricar do turismo com a conservação ambiental, pois possuem como característica principal a adesão voluntária de seus proprietários. O estímulo à criação de novas reservas e promoção da conservação da natureza pode provocar um efeito multiplicador por toda a sociedade quanto ao aumento de consciência da importância da natureza. O fato de existirem quase 1000 RPPNs no país, presentes em todos os estados e biomas naturais, apesar de apenas duas décadas de vida legal, já denota sua importância. Mais ainda, face às ações de uso público identificadas em várias delas, conforme CNRPPN (2010).

Como continuidade e ampliação deste estudo sugere-se a realização de levantamento longitudinal (por meio de questionários, entrevistas e/ou visitas 'in loco') sobre os fatores determinantes para que proprietários de terras decidam estabelecer RPPNs e as condições de sustentabilidade mediante os resultados alcançados com as atividades de uso público desenvolvidas. Poderá se verificar assim, se estas atividades de fato contribuem com a geração de oportunidades de empregos, renda e desenvolvimento sustentável e, sobretudo, no auxilio ao enfrentamento e redução dos efeitos na natureza oriundos do viver humano.

\section{REFERÊNCIAS}

Almeida, F. (2002). O bom negócio da sustentabilidade. Rio de Janeiro: Nova Fronteira.

Bellen, H. M. V. (2005). Indicadores de Sustentabilidade: uma análise comparativa. Rio de Janeiro: FGV.

Beni, M. C. (2003). Globalização do turismo: megatendências do setor e a realidade brasileira. São Paulo: Aleph.

Beni, M. C. (2007). Planejamento estratégico e gestão local/regional do turismo. In G. Seabra, (Org.), Turismo de base local: identidade cultural e desenvolvimento regional (pp. 125-150). João Pessoa: Universitária UFPB.

Braga, D. C. (2003). Investigação da demanda turística como fator fundamental para o planejamento e o desenvolvimento do turismo. In M. Rejowski, \& B. K. Costa (Orgs.), Turismo contemporâneo: desenvolvimento, estratégia e gestão (pp. 43-60). São Paulo: Atlas.

Revista de Gestão Social e Ambiental - RGSA, São Paulo, v. 5, n. 3, p. 116-134, set./dez. 2011. 
Câmara, I. de G. (2002). A política de unidades de conservação - uma visão pessoal. In M. S. Milano (Org.), Unidades de conservação: atualidades e tendências (pp.163-169). Curitiba: Fundação O Boticário de Proteção à Natureza.

Câmara, I. de G. (2004, outubro). As unidades de conservação e o paradigma de Durbain. Natureza \& Conservação. Revista Brasileira de Conservação da Natureza, 2 (2), pp. 08-14.

Confederação Nacional de Reservas Particulares do Patrimônio Natural. (2010). Recuperado em 03 abril, 2010, de http://www.rppnbrasil.org.br

Comissão Mundial de Meio Ambiente e Desenvolvimento. (1991). Nosso futuro comum (2a ed.). Rio de janeiro: FGV.

Dias, R. (2003). Planejamento do Turismo: política e desenvolvimento do turismo no Brasil. São Paulo: Atlas.

Dias, R. (2008). Turismo sustentável e meio ambiente (1a ed., 4. reimpr.). São Paulo: Atlas.

Donaire, D. (1999). Gestão ambiental na empresa (2a ed.). São Paulo: Atlas.

Egri, C. P., \& Pinfield, L. T. (2007). As organizações e a biosfera: ecologia e meio ambiente. In S. R. Clegg, C. Hardy, \& W. R. Nord (Orgs.), Handbook de estudos organizacionais: Vol. 1. Modelos de análise e novas questões em estudos organizacionais (1a. ed., 4a. reimpr., pp. 363-399). São Paulo: Atlas.

Hauff, S. N. (2004, outubro). Percepção de comunidades rurais sobre a implantação de Unidades de Conservação: subsídios para estabelecer zonas de amortecimento. Natureza \& Conservação. Revista Brasileira de Conservação da Natureza, 2 (2), pp. 32-47.

Instituto Chico Mendes de Conservação da Biodiversidade. (2010). Recuperado em 10 março, 2010, de http://www.icmbio.org.br

Instituto Brasileiro do Meio Ambiente e dos Recursos Naturais Renováveis. (2005). Recuperado em 04 janeiro, 2010, de http://www.ibama.gov.br/siucweb/rppn/

Magnanini, A. (2002). Política sobre as unidades de conservação - dificuldades e sucessos no pensamento de Alceo Magnanini. In M. S. Milano (Org.), Unidades de conservação: atualidades $e$ tendências (pp. 151-160). Curitiba: Fundação O Boticário de Proteção à Natureza.

Milano, M. S. Por que existem as unidades de conservação? In L. G. G. Trigo (Ed.), Análises regionais e globais do turismo brasileiro (pp. 193-208). São Paulo: Roca.

Ministério do Meio Ambiente, \& Instituto Chico Mendes de Conservação da Biodiversidade. (2007). Unidades de conservação do Brasil. Brasília: Autores.

Ministério do Turismo. (s/d). Plano Nacional de Turismo 2007/2010. Brasília: Autor.

Nobre, M., \& Amazonas, M. de C. (Orgs.). (2002). Desenvolvimento sustentável: a institucionalização de um conceito. Brasília: IBAMA.

Oliveira, J. A. P. de. (2003). Governmental responses to tourism development: three Brazilian case studies. In Tourism Management, 24, pp. 97-110. 
Organização Mundial do Turismo. (s/d). Recuperado em 14 janeiro, 2010, de http://www.unwto.org/aboutwto/why/sp/why.php?op=1

Pádua, M. T. J. (2002). Unidades de conservação muito mais do que atos de criação e planos de manejo. In M. S. Milano (Org.), Unidades de conservação: atualidades e tendências (pp. 7-13). Curitiba: Fundação O Boticário de Proteção à Natureza.

Petrocchi, M. (1998). Turismo: planejamento e gestão. São Paulo: Futura.

Pires, P. dos S. (2002). Dimensões do ecoturismo. São Paulo: Senac.

Pires, P. dos S. (2005). Entendendo o turismo. In L. G. G. Trigo (Ed.), Análises regionais e globais do turismo brasileiro (pp. 483-494). São Paulo: Roca.

Programa das Nações Unidas para o Meio Ambiente, \& Organização Mundial do Turismo. (2005). Por un turismo más sostenible: guia para responsables políticos. Autores.

República Federativa do Brasil. (2000). Lei no 9.985, de 18 de junho de 2000 que Regulamenta o art. 225, $\S 1^{\circ}$, incisos I, II, III, e VII da Constituição Federal, institui o Sistema Nacional de Unidades de Conservação da Natureza e dá outras providências. Recuperado em 14 janeiro, 2010, de http://www.planalto.gov.br

Sachs, I. (2008). Caminhos para o desenvolvimento sustentável (3a. ed.). Rio de Janeiro: Garamond.

Sen, A. K. (1999). Desenvolvimento como liberdade. São Paulo: Companhia das Letras.

Soldatelli, M. (2005). Impactos ambientais negativos no contexto do turismo de natureza. In L. G. G. Trigo (Ed.), Análises regionais e globais do turismo brasileiro (pp. 517 - 536). São Paulo: Roca.

Veiga, J. E. (2008). Desenvolvimento sustentável: o desafio do século XXI (3a. ed.). Rio de Janeiro: Garamond. 
Data do recebimento do artigo: 13/10/2010

Data do aceite de publicação: 07/12/2012 